\title{
CHANGES IN THE CULTURAL VALUE OF THE ETHNIC CHO-RO IN DONG NAI PROVINCE, VIET NAM
}

\author{
Assoc. Prof, Dr. Lam Nhan \\ Ho Chi Minh City University of Culture, 51 Quoc Huong Street, Thao Dien Ward, District 2, Ho \\ Chi Minh City, Vietnam \\ Email ID: lam_nhan@yahoo.com \\ D.O.I-10.51201/JUSST/21/05153 \\ http://doi.org/10.51201/JUSST/21/05153
}

\begin{abstract}
In the last decades of the twentieth century and the beginning of the twenty-first century, Vietnam entered a period of strong industrialisation and modernisation. The growth rate of industrialisation and urbanisation in Dong Nai Province is very high, thus speeding up the process of modernisation. The rapid economic growth helps to improve the material and spiritual life of the people. In addition to economic development, new cultural and social issues have also emerged, especially changes in the cultural values of minority communities. This article studies the cultural changes of the ethnic Chơ-ro in Dong Nai Province. These changes stem from environmental changes such as life and economic activities and cultural exchange with other races living in the same area. Such changes are inevitable in ethnic minority communities in Vietnam. However, for the Cho-ro people, this trend of change has become more intense, because people's living environment has been greatly embroiled since 1950s. In addition, there is no emotional connection between their religious mentality, customs, and daily life. The traditional cultural value of Cho-ro will gradually disappear under the current momentum and will be replaced by a new cultural value system.
\end{abstract}

Keywords: cultural change, Cho-ro, modernization, Dong Nai, Vietnam

\section{Introduction}

In Dong Nai Province, the Cho-ro is one of the important indigenous ethnic minorities. During the history, the Chơ-ro established their status with a clear social, cultural, and social backgrounds. The Cho-ro and other groups are part of Vietnam's cultural diversity and are deeply involved in cultural exchanges locally. They are always looking for a model of cultural development to make progress while maintaining ethnic cultural identity.

The Cho'-ro is one of the indigenous peoples who have long lived in the eastern subregion of southern Vietnam. Due to the previous wars, the living conditions in the area experienced many fluctuations. Chơ-ro people always have to relocate their residential area, so that cultural values gradually disappear. Today, in the period of strong international exchange and integration, the Cho'ro's cultural values are facing challenges in maintaining and promoting ethnic cultural identity.

Studying the cultural changes in the Cho-ro community at this stage is a necessary and urgent task to identify the problems of cultural preservation, modification, and integration. It is very important to point out the basic and valuable values that must be retained and improved through academic research, as well as inappropriate values that will be automatically eliminated. This situation requires a long, serious, and thorough research process. Within the scope of this article, the author focuses on the issues of cultural exchange and adaptation, as well as the changes in the Cho-ro community in the current period. This is a broad and difficult topic that requires time and energy. 
What the author provides in this paper are preliminary studies that can lay the foundation for future research.

\section{Literature Review}

So far, many writers have studied the ethnic Cho-ro people from the aspects of history, archeology, ethnography, culture, religion, medicine, economics, etc. In the mid-20th century, French scholars mentioned the Chơ-ro for the first time in their research. However, these documents did not directly and deeply study Cho-ro culture, but slightly compared the living style of the Cho-ro with the neighbouring Mạ community. Among these works, The Land of the Mạ by Boulbet (1967) is an example.

During the period from 1954 to 1975, for many objective reasons (warfare and the temporary decline of academic research), there was no research on Chơ-ro people. Until 1975, due to the need for national unity and social integration, domestic scholars began to study this community in many fields such as agricultural technology, folk religion, folk art, customs, folk architecture, and handicrafts. In these studies, two books must be mentioned, namely Issues of Ethnology in South Vietnam, 1978 and Ethnic Minorities in southern provinces of Vietnam, 1984. In addition, Central Highlands Plateau: Potential and Prospects, 1992) also made important contributions to the understanding on the Cho-ro. It can be said that these are the first ethnographic works on the ethnic Cho-ro community in the academic world.

The following are some general studies of Cho-ro people in 54 ethnic communities in Vietnam. Firstly, it was the work Pictures of Vietnamese Ethnic Groups published in 1997. In the report Vietnamese Minorities in the Twentieth Century, published in 2000, the Cho-ro as a part of the indigenous peoples of Dong Nai and Ba Ria-Vung Tau provinces were introduced. Other folk literature works, some of which mention the Chơ-ro community, have also been published, such as Vietnamese Traditional Houses, 1994, Culture and Ethnic Identity in Dong Nai, 1998, etc. These works do not focus on the Cho-ro community but place the community in the multi-ethnic background of the area.

Especially recently, there are 3 in-depth research works on Chơ-ro people, including Ngườ Châu Ro ơ Dong Nai (The Châu Ro people of Dong Nai, 1998), The Marriage and Family of the ethnic Choro of Dong Na, Tradition and Change, 2010, and The culture of the ethnic Cho-ro, 2013. Part of the cultural change of the Chor-ro community is mentioned; however, they do not cover the entire culture.

In general, all of the above-mentioned studies have introduced the traditional Cho-ro culture from both two aspects of tangible culture and intangible culture. This article studies the changes in Cho-ro culture in Dong Nai from the perspective of cultural changes.

\section{An overview of the Cho'-ro in Dong Nai}

\section{Results and Discussion}

Figure 1 \& 2: Map of Vietnam and Dong Nai Province, in which the Cho-ro quarters are highlighted. 


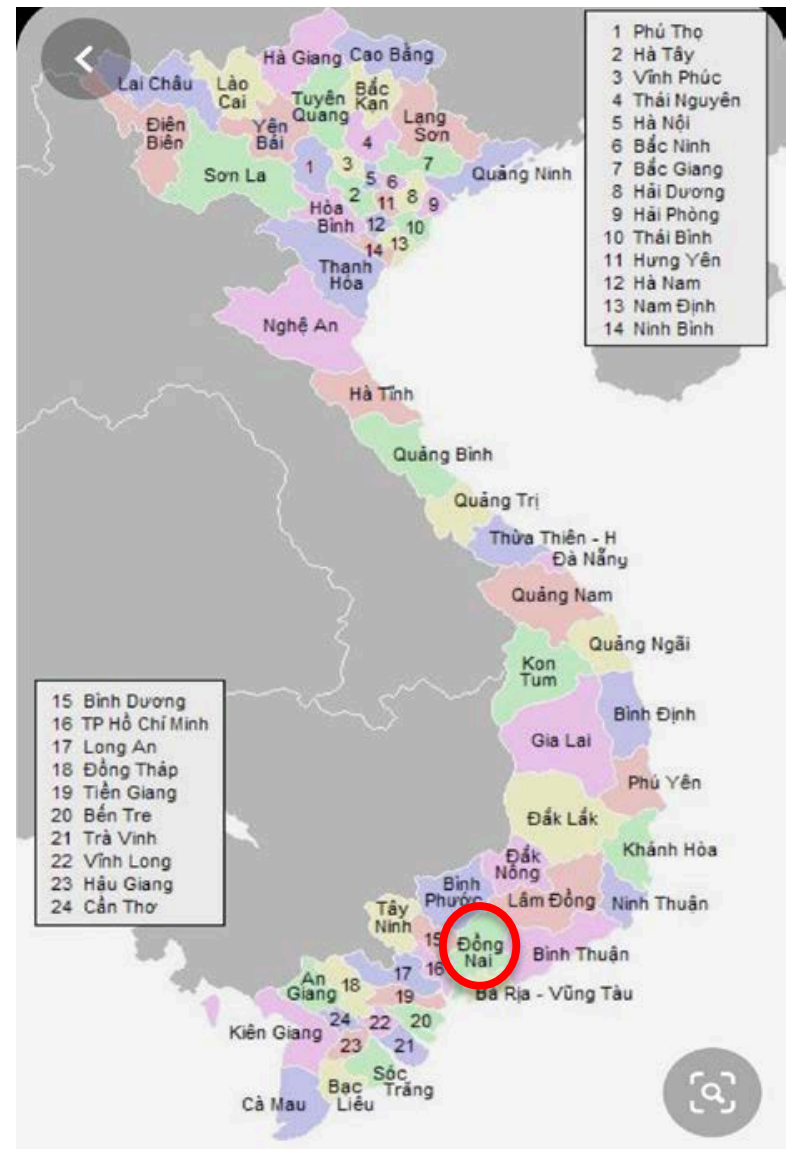

Vietnam map

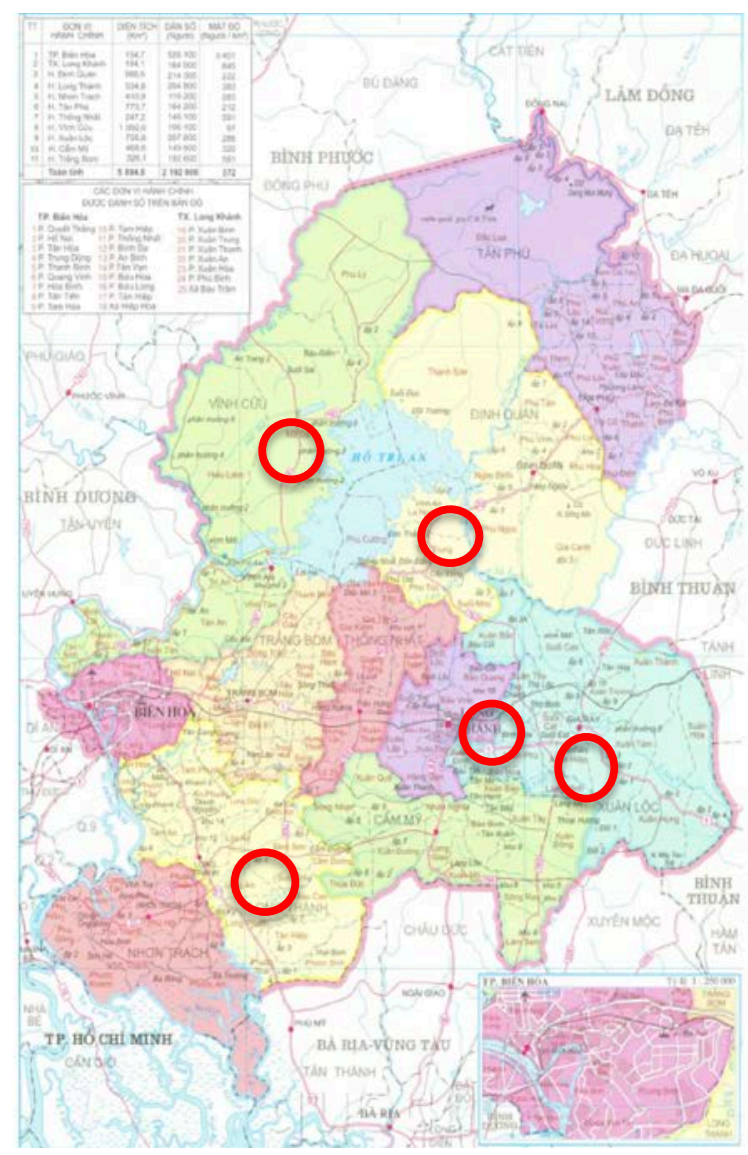

Dong Nai map ${ }^{1}$

Today, there are more than 28,655 Cho-ro people in Vietnam (General Statistics Office, 2019). Most of them live in Dong Nai Province. The full name of this group is "Chrau Jro", in which "Chrau" means "a group of people or a community" and "Jro" is their self-proclaimed name (see Institute of Ethnology 1984: 205). They are also called by nouns of similar sounds, e.g., Chơ-ro, Châu-ro, Chro, Chrau, Jơ-ro, Dơ-ro, etc., or the term "người Mọi (the Montagnard)".

According to Schliesinger, the Cho-ro has been differently identified in three different classifications. In the first classification, in 1959, "the Cho-ro is a native subgroup of the Mạ people". In the second classification, in 1973, 59 ethnic groups were listed but the name "Cho-ro" was not on the list. The third classification in 1979 identified 54 ethnic groups. The Cho-ro has been formally included in the list. They belong to the Mon-Khmer language family and are an independent group (Schliesinger, 1997: 12-19).

The ancestors of the Cho-ro were the ancient Mon-Khmer inhabitants who widely lived in the mountains of southern Indochina a long time ago. Before the Cho-ro appeared in the current residential area, they had mainly distributed in the low mountainous areas in the southeast of Dong Nai. They belong to the southern mountainous branch of the Mon-Khmer language family. According to the results of archaeological research in the eastern subregion of southern Vietnam and related anthropological and linguistic research, the current Chơ-ro and the Mạ and Stiêng are descendants of the ancient indigenous Mon-Khmer subgroups of the local area. The lives of these groups are now more or less closely connected, which fully reflects the original relationship between them, and at the same time, it is conducive to managing a larger living area. In Dong Nai province, a

${ }^{1}$ www.pintest.com/pin83858 
total number of 16,738 Chơ-ro people are mainly living in 5 districts and towns, including Long Khánh, Xuân Lộc, Định Quán, Vĩnh Cửu, and Long Thành (Dong Nai Statistical Office 2019: 105).

The Cho-ro traditional economy is based on agricultural cultivation. In the past, people used the hills and mountains where they lived for nomadic farming and seasonal cultivation, so their lives were normally poor and unstable. Later, people learned how to turn dry fields into permanent farmland and paddy wetlands, and developed better farming methods so that their lives would be better. Like rice agriculture, plateau farming, gardening, animal husbandry, hunting, fishing, and gathering activities provide a secondary source of income. The two main handicrafts of the Cho-ro community are wood weaving and brocade weaving. However, only bamboo and rattan weavings were popular. However, due to the introduction and dominance of industrial weaving products, the traditional weaving of the ethnic Chơ-ro was gradually weanking and is now completely gone.

The Chơ-ro folk culture is rich and diverse. They are famous for oral stories, lyric poems, dances, reciprocal singing styles, multiple musical instruments, etc. Cho-ro proverbs and idioms are also very rich, vividly summarizing the experience of agricultural production, the experience of dealing with nature and social life.

The Chơ-ro believe that everyone/everything has a soul, and at the same time believe in the rule of the spirit over mankind. Therefore, the Chor-ro is very keen on rituals and taboos. These communities believe that there are two worlds. The first world is where humans live, where people can see and feel everything. The second is the world of supernatural powers, including places where gods, demons and other invisible souls live. According to the Cho-ro's faith, the second world is sacred and determines human life. For them, the shaman woman (chang) functions as a 'bridge' to link man and gods/spirits. Their main gods include the god of rice (yang va), the god of the forest (yang bri), the god of rivers and the streams (yang dah), the god of rice-fields (yang mir), and the god of highland farms (yang mo), etc. Basically, the Cho-ro's spiritual life is very similar to that of the nearby Mạ and Stiêng communities, which are mainly based on animism. This belief has existed for thousands of years, but with today's dramatic changes, it is incapable to just unite and internalise the community as before. Compared with Cho-ro, the religious life of the Khmer people ${ }^{2}$ living in neighbouring Bình Phước or Tây Ninh provinces and the Mekong Delta is well-organised. They practice Mahayana Buddhism, which closely connects communal life with temples, monks, and Buddhist principles. Our preliminary investigation shows that under similar pressures of industrilaisation and modernisation, the Khmer people are more active in modernizing their physical and mental lifestyles and are able to maintain their religious life, customs and community cohesion.

\section{Changes in the cultural value of the Cho'-ro community}

Overall, despite the tremendous changes in lifestyle, the Cho-ro community in Dong Nai still retains some traditional cultural elements to a certain extent. However, in any field, it is easy to see the existence of a new value, and it is not uncommon to see new value standing in a dominant position in specific fields. Under the influence of the ecological environment and policies aimed at the developments of ethnic minorities in the province, economic life has undergone profound changes in every level. Many customs that have been practiced for many centuries are no longer relevant to the current social environment and are gradually rejected by the community.

The change of Chơ-ro culture was also greatly influenced by other nearby ethnic cultures, especially the Vietnamese. Through cultural exchanges, they have absorbed many cultural values of the

\footnotetext{
${ }^{2}$ Another Mon-Khmer ethnic group living in southern Vietnam. In the Kingdom of Cambodia, the Khmer are the majority group.
} 
Vietnamese living in the same place, such as doing business, housing, clothing, language, and customs. This change is more intense in places where residents have more regular contact with Vietnamese, for example, the Chơ-ro quarters in Túc Trưng commune in Định Quán District.

Nowadays, various ethnic groups have been strengthened and expanded day by day in terms of communication and contacts between regions. Each race is more likely to absorb the cultural values of other races. However, due to low self-esteem and misunderstanding of ethnic culture, many Choro people think that their traditional values are outdated and backward, and tend to deny them. At the same time, they freely accept the cultural values of other groups with higher levels of socioeconomic development. Therefore, if an ethnic community does not adopt new values through creative choices and adaptations (to its existing cultural values), this can easily lead to the easy loss of its ethnic cultural identity.

\subsection{Vietnamese influence on the Cho-ro culture}

\section{Economic activities}

The shift to sedentary planting, stable settlement, and access to more advanced farming methods of the Vietnamese marks very important and decisive change in the overall socio-economic development of the Chơ-ro community. Chơ-ro people have very few old tools. So far, they have received more Vietnamese agricultural tools and equipments (such as plowing machine, digger machine, rice harvesters, lawn mowers, etc.). Today, Chơ-ro people have widely used Vietnamese agricultural calendar and technical measures for rice planting, irrigation, and fertilisation, etc.

The economic activities of the Vietnamese have had a great impact on ethnic minority communities living in general areas. The Chơ-ro community is not excluded. In terms of production and material life, this has positively promoted the economic development of the Cho-ro.

In recent years, under the influence of market mechanisms, the Cho-ro's use of nature and a selfsufficient economy still exist. At the same time, the commodity economy has penetrated and deeply rooted in people's lives. Many Chơ-ro people participate in business activities and become small merchants in the local markets. They sell vegetables, tubers, and fruits. In some places, some families have opened coffee shops and food shops. Initially, production investment has been extensive. Most families bought farm machinery (Lam, 2010: 53). However, due to the lack of capital and technical knowledge, as well as the lack of a stable consumer market, the development of the commodity economy still faces many difficulties and is therefore greatly restricted.

\section{Social aspect}

In society, the most obvious influence of Vietnamese on the Chơ-ro community is their surname. For many reasons, Chơ-ro people use Vietnamese surnames as their surnames. In Phú Lý commune (Vinh Cuu District), most Chơ-ro people have the Vietnamese surnames of Nguyễn and Hồng. In addition, interracial marriages between Chơ-ro and Vietnamese are very popular. Many Chơ-ro men marry Vietnamese women and vice versa. For example, in Ms. H.T.L.'s family in Lý Lịch 2 hamlet (Phu Ly commune, Vĩnh Cửu District) 4 out of 7 children are married or married to a Vietnamese spouse (fieldwork notes, 2015). For the Cho-ro ethnic group, when marrying a Vietnamese, all marriage procedures, rituals, and regulations should comply with Vietnamese customs. The interracial marriage between the Cho-ro and the Vietnamese is both an expression and a result, and it is also a driving force for cultural exchanges between the Cho-ro and the Vietnamese communities.

At present, many Chơ-ro life-circle customs are also influenced by the Vietnamese. The Chơ-ro's wedding sequence is almost the same as that of Vietnamese weddings, including going to the match-making meeting, engagement, marriage, etc. In addition, the Vietnamese customs of 
"checking for the fortunate time" 3 also affect the Chơ-ro, especially when they organise important tasks such as weddings, funerals, house construction, business opening, etc.

Tangible culture

For a long time, Vietnamese tailor-made clothes have been widely used. Except for special occasions (such as artistic performances), Chơ-ro ethnic costumes no longer appear in the community. Most of Chơ-ro women in Túc Trưng commune (Dinh Quan District) wear áo dài ${ }^{4}$ during Tết holidays ${ }^{5}$, in church services, weddings, and other ceremonies.

In terms of diet, Cho-ro people use a variety of new foods to prepare and cook dishes that have never been eaten in the past. Traditionally, due to difficult living and economic conditions, they paid little attention to food processing. Food processing used to be simple, including boiling, roasting, and steaming. Currently, they learn to make spring rolls, phở, and other dishes like normal Vietnamese families. The use of industrially produced seasonings (such as monosodium glutamate, soup powder, etc.) in food and the use of sauces (such as fish sauce and soy sauce) in meals instead of traditional chili salt have also become popular.

In terms of housing, due to currently sedentary farming and settlement, and in accordance with the state policy of building nhà tình thuoong ("love-sharing" houses) ${ }^{6}$ for the poor and the ethnic minority, unstable stilt houses are gradually being replaced by stronger concrete houses for longterm use. Nowadays, there are many Vietnamese flat roofs in the Cho-ro quarters. At the same time, due to lack of materials, especially wood, houses on stilts have become rare, so Chơ-ro people have gradually become accustomed to living in ground-surfaced houses. In Trung Sơn hamlet (Dinh Quan District), houses on stilts completely disappeared. With the formation of more and more groundsurfaced houses, stilt houses are gradually being replaced and it is difficult for them to retain the traditional elements of traditional house design and construction. However, spiritually speaking, Chơ-ro people still like to live in stilt houses. Some families in Lý Lịch 2 Hamlet are granted "lovesharing" houses, but they do not live in them. Instead, they still live in their old houses on stilts. In recent years, many urban Vietnamese have moved to ethnic minority areas to buy traditional wooden houses on stilts. Usually, before the harvest season when the Chor-ro community is short of financial budget and foodstuff, many of them wander the Cho-ro neighbourhood to persuade the locals to sell their wooden houses. In 2013, the author got the news in Da Hoai District (Lam Dong province) that sold his wooden house for 70 million VND. The buyer paid 50 million VND in cash and built a brick house worth 20 million VND. Only when the brick house was finished, the buyer would take the wooden house away (fieldwork note, 2013).

Therefore, according to the survey results of the Socio-economic Conditions of 53 Ethnic Minorities collected by the Statistics Bureau in 2015, the proportion of the Cho-ro who own traditional stilt wooden houses is 0.5\%, the Stiêng 1.6\%\%, and the Mạ 1.0\% (the Statistics Bureau 2015). As a result, among the three ethnic minorities the author observed, the Chơ-ro community has the lowest proportion of traditional houses. According to this trend, the traditional houses of Cho'-ro people will appear in the movie only if the intervention of the competent authorities at all levels is not punctual and effective.

\footnotetext{
${ }^{3}$ It is fortune-telling based on the zodiac and is widely used to check lucky/taboo days and times.

${ }^{4}$ Vietnamese national costume for women.

${ }^{5}$ The Vietnamese Lunar New Year.

${ }^{6}$ Houses built by the government to grant to the poor, the meritful, and the ethnic minority.
} 
Intangible culture

As an indigenious group living in southern Indochina for a long time, but today, due to living closely with Vietnamese, Cho'ro people can speak fluent Vietnamese. Due to many different economic, cultural and social reasons, Vietnamese language is becoming more and more popular in Cho-ro communities. They speak Vietnamese at community meetings, shopping and other social gatherings. The children go to school in Vietnamese. On the other hand, due to regular contact and communication with Vietnamese people, even in Chơ-ro language, a large number of Vietnamese words are increasingly involved in Chơ-ro language. Social and professional technical terms, such as Tết, culture, backpacks, shoes, glasses, curling tongs, lighters, books, newspapers, football, news, movies, etc., are all mixed in the native language of the Cho-ro.

Currently, most Cho'-ro people between 18 and 50 in Dong Nai are good at Vietnamese. Many Cho-ro youths living near highways or urban areas do not even understand their mother tongue. For example, the Chơ-ro in Định Quán District cannot speak the Chơ-ro language fluently. On the contrary, their daily communication language is Vietnamese. There is a difference between Cho-ro and Khmer. The Khmer community strongly practices Southern Buddhism and always associates their indigenous language with ritual activities, so their language is well preserved. Only some new technical terms can be successfully absorbed into the Khmer language. In the Cho-ro community, the animist faith is no longer effective. In addition, the close coexistence of the Vietnamese makes it easier for them to accept new elements in language and culture. In addition, Cho-ro people were called the "Moi (Montagnard)" by the French for a long time since the beginning of the 20th century. Later, some Vietnamese continued to call them that way. During our field trips in 2009 in Túc Trưng commune of Định Quán District, the local Chơ-ro became very angry if some one used this term to address their raising animals or dishses (such as heo mọi (montagnard pig), nuóng mọi (montagnard-style grill), etc.) ${ }^{7}$. Many of them emphasised that this stereotype played down their status. Therefore, many people try to deny local identities, especially the ethnic language.

\subsection{The cultural influence between the Cho-ro and the Mạ, the Stiêng, and other indigenous groups}

Because they live in the same place and have the same focus on economic resources, the Cho-ro community has a close relationship with other neighbouring groups (such as the Mạ, the Stiêng, etc.). This relationship has been formed for a long time and is reflected in many aspects of history and culture. This is a bilateral relationship. In general, the Chơ-ro, the Mạ, the Stiêng, the Cơ-ho, and other indigenous groups all have the same Mon-Khmer linguistic origin and cultural background. Therefore, it is difficult to determine the impact of one group's cultural factors on another nation, and vice versa.

Chơ-ro, Mạ, Stiêng, and other ethnic societies in this area have complete social characteristics of the transition from matriarchy to patriarchy. This is the first similarity to be mentioned. The characteristics of patriarchy have become more and more obvious nowadays. Traditionally, the newlyweds once lived in the wife's residence. However, the form of living bilaterally and then living separately has emerged and prevailed. The role of family leadership has also shifted from women to men.

\footnotetext{
${ }^{7}$ The current Vietnamese no longer call the peoples of the mountains "Mọi"; however, the term is still used to address certain objects and animals related to these groups.
} 
The mutual cultural influence of these peoples is reflected in all aspects of their social and cultural life, from production methods to rituals in the life cycle. Typically, Cho-ro brocade weaving vividly shows the cultural influence of neighbouring groups. Some patterns on Cho-ro clothes do not have their own ethnic names but are normally called "the Mạ pattern", "the Cơ-ho pattern", "the Stiêng pattern", etc.

In folk beliefs, the mutual influence of indigenous peoples in the same area is obvious. The first is the gods (yang). The Mon-Khmer speaking groups in this area (Chơ-ro, Mạ, Stiêng, and Cờ-ho) have strong faith in gods and regularly hold rituals dedicated to them. In agricultural ceremonies, the role of shamanic women is obviously similar. They all have a common concept of life and death.

Because they live in the same area and have close connections and exchanges with each other, the traditional dances of the Chơ-ro, Mạ, and Stiêng have many common features. They all fully reflect the living environment and the way humans interact with nature, create wealth, and create tangible and intangible cultures. They also show the community's thoughts and beliefs in God, and the desire to overcome all the difficulties in life.

Compared with the above-mentioned Mon-Khmer speaking groups in Dong Nai, the Khmer ethnic group in the Mekong Delta follows Theravada Buddhism. Individuals are neatly tied with their families, temple communities, and the entire village. Khmer villages usually settle near temples, and their religious activities and customs are closely related to these institutions. Young Khmer males are encouraged to study Buddhist philosophies and life skills in local temples for one or two years. As a result, the community is closely connected and internalised, which, to a certain extent, functions as a "wall" that helps protect the ethnic cultural identity. The Chơ-ro, Mạ, and Stiêng are not similar. At present, the ties between individuals in each ethnic group are loose, and cultural exchanges between these groups are also weak and spontaneous.

\section{Cho-ro culture in the current context}

Nowadays, the lives of Cho-ro people have become more stable and their incomes are getting higher. Life is getting better, and everyday appliances are becoming more modern and comfortable. Today, most of their household appliances are industrial products made of aluminum or plastic materials. Many well-off families bought expensive items such as beds, wardrobes, TVs, motorcycles, etc. Since mid-2003, many Chơ-ro neighbourhoods have connected the national electricity network. For example, 100\% of Chơ-ro households in Trung Sơn Hamlet of Xuân Trường Commune in Xuân Lộc District own a TV (fieldwork notes, 2015). In other hamlets/villages, the proportion of households with TV is lower. According to the 2015 National Bureau of Statistics survey on the socio-economic conditions of 53 ethnic minorities, the number of Cho-ro households who own motorcycles accounted for $82.3 \%$. This proportion is $90 \%$ in the Ma community and $85.5 \%$ in the Stiêng community. The proportion of Chơ-ro households with TV is 90.5\%, Mạ is 91.0\%, and Stiêng is $85.2 \%$. 71.1\% of Chơ-ro households have telephones, while the Mạ accounts for 70.9\%, and the Stiêng accounts for only 59.1\%. Meanwhile, for sturdy houses, the proportion of the Cho-ro is 5.1\%, the Stiêng is 5.2\%, and the Mạ is only 3.2\% (General Statistics Office, 2015). Therefore, the permanent residence of the Mạ is lower than that of the Stiêng and the Chơ-ro, but they use more modern living facilities than the Chơ-ro and the Stiêng. Generally speaking, the indigenous minorities in Dong Nai and neighbouring provinces use many modern and convenient technical means in daily life. This may also be the reason why they prefer other ethnic cultures/civilisations, which makes their own culture gradually fade out.

The current Cho-ro people know how to use modern machines to mechanise agriculture. Harvesters and rice threshers are widely used, reducing physical labor in farming. They also use pesticides and 
fertilisers in agriculture. For animal husbandry, natural animal feed is gradually being replaced by industrial products. The form of grazing livestock has been changed to centralised breeding, and animal houses have been established for each species. Although the application of new technological advancements among the Cho-ro is still restricted and only at the beginning stage, this has made their lives less difficult.

Under the industrialisation impact, Cho-ro people are no longer confined to the area where they live due to the increasing demand for living standards. Many Chơ-ro youths get a job in the industrial zones. Some people in the hamlets of Đồng Xoài and Đức Thắng in Túc Trưng Commune (Dinh Quan District) cooperated financially, bought saws and wooden rickshaws, and engaged in hired works in Laos ${ }^{8}$.

Due to the current trend of communication and integration, the Cho'-ro's clothes and adornment have also undergone many changes. In addition to modern Vietnamese clothing, Chơ-ro women also wear long skirts on special occasions. Young people prefer to wear jeans and T-shirts. Traditional necklaces, bracelets, rings made of beads, plastic beads, etc. are now made of different materials. Today, at the wedding, the Cho-ro groom wears suits and leather shoes; the bride wears high heels, long dresses, and modern jewelry.

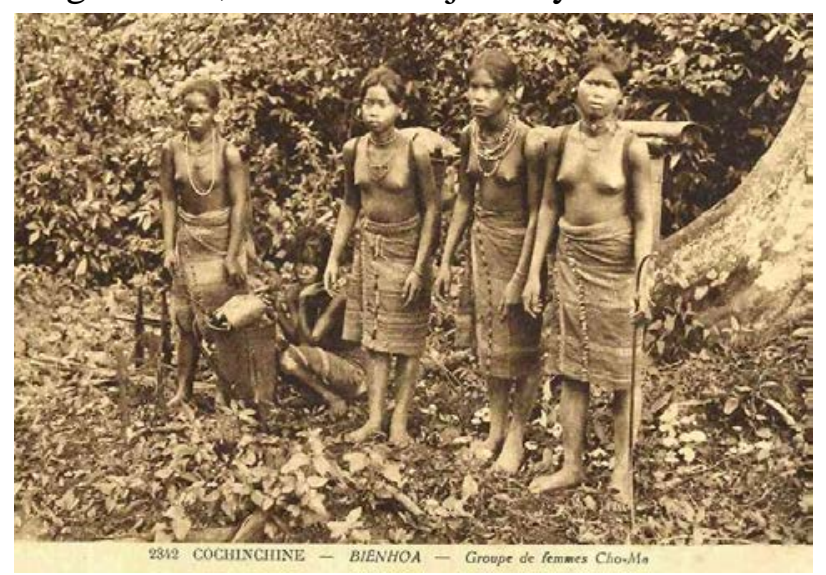

Figure 3: The Cho'ro women in 1945, Documentary photo in Dong Nai Museum

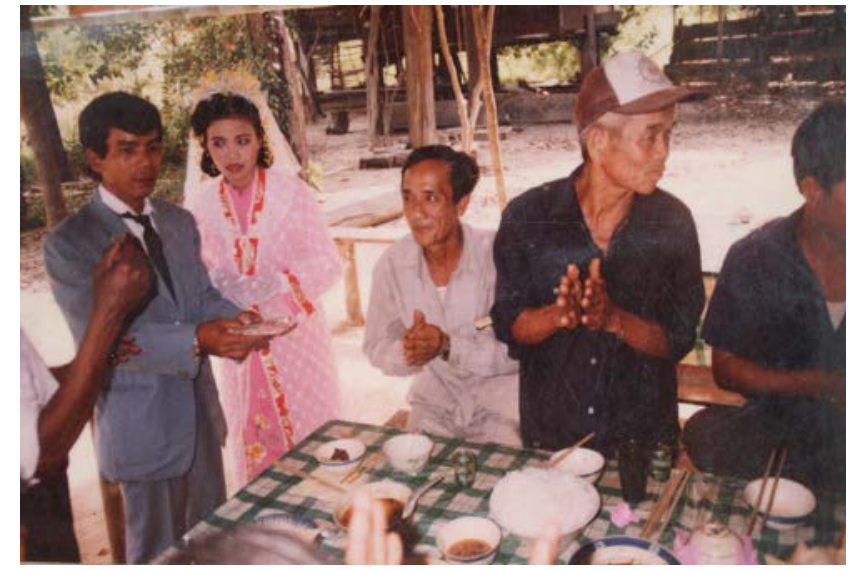

Figure 4: A Cho-ro wedding in 2015 (Photo Author)

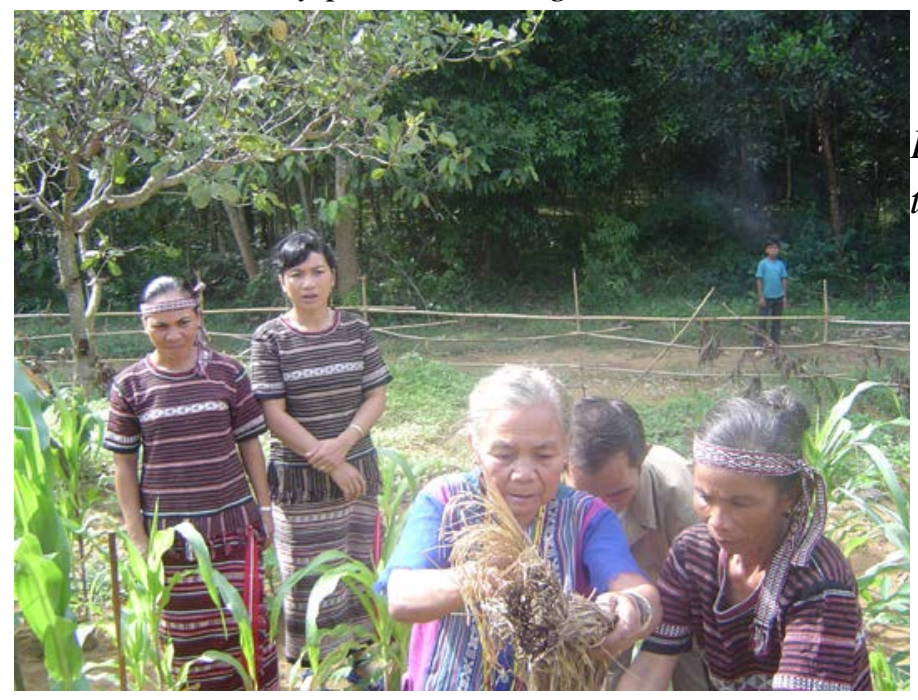

Figure 5: Cho'ro ceremonial costume today the Yang Va ceremony (Photo: Author, 2010)

Nowadays, Chơ-ro people rarely follow the guidelines of shaman women to cure diseases. Instead, they come to regional health institutions for medical examinations and childbirth. However, for

\footnotetext{
${ }^{8}$ Interview with Mr. Đ.S. in Đức Thắng Hamlet, Định Quán District in 2012.
} 
some simple diseases, such as abdominal pain, headache, eye pain, dislocation, insect bites, etc., village chiefs in certain places (such as Vinh Cuu, Xuan Loc, Long Khánh, etc.) still use traditional forest leaf treatment methods. In places with developed economy and well-developed transportation, they often go to the hospital and use western medicine and medicinal oil when they are sick. The methods of raising children are also under the guidance of community health workers. The health of children and the elderly is better than many years ago. The marriage age of Cho-ro men and women is also higher. Weddings and funerals are held in an orderly and well-organised manner, not as complicated and lasting for many days as they used to.

The spiritual life of Chơ-ro people is also undergoing tremendous changes. The habitat of Cho-ro has largely changed. There are no more forests around their residential areas; instead, factories and export processing zones have sprung up. Economic life has changed, and the traditional highland agriculture of seasonal farmland has been replaced by perennial industrial crops such as rubber, coffee, and tea. The Cho-ro community no longer depends on forest and plateau agriculture, so the custom of worshiping the forest god (yang bri) and other related deities gradually disappeared. When traditional spirits disappear, newly introduced religions will appear. The introduction of Catholicism and Protestantism, especially in recent years, has had a huge impact on the traditional culture of Cho-ro people. Many Chơ-ro hamlets have been converted into Protestant quarters. This has led to changes in traditional cultural lifestyles. Community activities are currently concentrated on church holidays. Gongs and traditional musical instruments are rarely used.

\begin{tabular}{|c|c|c|c|c|c|}
\hline Ethnic group & $\begin{array}{c}\text { Buddhism } \\
(\mathbf{\%})\end{array}$ & $\begin{array}{c}\text { Catholicism } \\
(\mathbf{\%})\end{array}$ & $\begin{array}{c}\text { Protestantism } \\
\mathbf{( \% )}\end{array}$ & $\begin{array}{c}\text { Islam } \\
\mathbf{( \% )}\end{array}$ & $\begin{array}{c}\text { Others } \\
(\%)\end{array}$ \\
\hline Chơ-ro & 31.4 & 13.1 & 20.8 & 0.1 & 0.2 \\
\hline Stiêng & 2.3 & 12.4 & 61.4 & 0.0 & 3.2 \\
\hline Mạ & 1.5 & 62.7 & 19.4 & 0.0 & 0.0 \\
\hline
\end{tabular}

Table 1: The main survey results of the General Bureau of Statistics collecting information on the socio-economic status of 53 ethnic minorities in 2015.

According to the above survey, the Mạ community has the highest proportion of Catholics (62.7\%) while the Stiêng has the highest proportion of Protestantism (61.4\%). Meanwhile, the proportion of Chơ-ro people who follow Buddhism is 31.4\% (compared to 2.3\% for the Stiêng and 1.5\% for the Mạ). In fact, in a field survey in 2014, the author found through attendance observations, in-depth interviews, and other qualitative research that most families who married a Vietnamese spouse practice Buddhism, while those who married to a spouse of the same ethnic group and with other ethnic minorities in the same area are either Catholic or Protestant. In the 1,200 questionnaires conducted by the Mạ community, no cases of Buddhism were found in families of the same race (see Lâm Nhân 2010). Therefore, it can be concluded that Chơ-ro people have more marriage relationships with Vietnamese than other ethnic minorities in the area. Therefore, the risk of losing its traditional cultural value is thus higher.

Various Western cultures spread to the region along with Catholicism and Protestantism, the most obvious of which are transmitted through books, newspapers, videotapes, television programs, and internet-based services. It is necessary to enter the new world culture. From a material and progressive point of view, it is reasonable to adopt the new cultural aspects of the world. However, people in certain regions, especially the younger generation, are under the excessive influence of foreign cultures, leading to many undesirable changes in social relations, aesthetics and moral concepts. From a more positive perspective, today's Chơ-ro teenagers have more entertainment 
options. They are free to participate in new entertainment activities, such as karaoke, western-style birthday parties, drinking coffee and chatting with friends, playing billiards, drinking beer and wine in collective parties, etc. Under this trend, people are more likely to accept the personal enjoyment of lifestyle and reduce the traditional community mentality. Ngô et al. (1998: 216) discussed this trend and pointed out that modernisation is essential to all communities, but this does not mean that modernisation denies traditional values.

The current cultural change in ethnic communities is inevitable. Transformation is a reasonable choice for the community. However, this change must have an impact on the cultural value of the community. Otherwise, industrialisation and the urban environment will have a greater impact on social economy, culture, and social life in the future, and lead to greater changes and erosion of ethnic cultural identities

\section{Conclusion}

In the process of studying the cultural changes of the Cho-ro ethnic group and other ethnic groups in the entire eastern subregion of southern Vietnam, the author makes some preliminary conclusions, as follows:

(1) In the context of interracial interaction, indigenous communities are absorbing the huge cultural influence of other races, among which the Vietnamese are the most influential. Compared with communities living in remote areas, ethnic communities living near administrative centers and national highways change their traditional culture more quickly;

(2)In the context of international integration, cultural exchanges have become increasingly fierce. Dong Nai province has established many industrial zones, making it an international province. People from all corners of the world are going to Dong Nai, causing more and more cultural interactions and exchanges. In the environment of indigenous peoples lacking inward spiritual connection in their traditional culture and are currently undergoing drastic changes, new and more pragmatic cultural values will be more easily accepted and applied.

(3) The Cho-ro and other ethnic groups in the area gradually lost their faith in polytheism. Similarly, the role of the sacred communal houses (community houses) that organised the worship ceremony of the gods gradually is fading out. It is this sacredness that will fade, leading to the loss of other cultural values. The author affirms that among ethnic minorities whose sacred communal houses are strictly protected (i.e., the Theravada Buddhist Khmer in the Mekong Delta and the Brahmanic Chăm in central Vietnam), their culture still retains many traditional values. In other words, in the context of integration, each culture is changing, but the social and sacred values of the community can be used as the driving force to maintain its traditional mentality.

(4) The Cho-ro in Dong Nai are easily caught up in the current economic, cultural, and social changes. Of course, when the community lacks the power of inward connection/internal cultural integration in community life, their religious beliefs and daily cultural customs will be easily changed. When people strongly acquire new and more modern customs, indigenous gods are forgotten, and sacred rituals are abandoned. Therefore, the stability and harmony of religion in ethnic communities and the promotion of the role of religion in maintaining traditional cultural values and ethnic awareness education are the most urgent requirements today.

\section{References}

[1] Anonymous. 2000. Vietnamese Minorities in the Twentieth Century. Hanoi: National Politics.

[2] Boulbet, J. 1967/1999. Pays des Maa: domaine des génies, Nggar Maá, Nggar, trans. Đỗ Van Anh. Biên Hòa: Dong Nai Publishing House. 
[3] Department of Ethnology. 1978. Issues of Ethnology in South Vietnam. Hanoi: Social Sciences.

[4] Dong Nai Folk Arts Association. 1998. The Châu Ro people of Dong Nai. Bien Hoa: Dong Nai Publishing House.

[5] Dong Nai Statistical Office. 2019. Dong Nai Statistical Yearbook 2019. Hanoi: Statistics.

[6] General Statistics Office. 2015. The General Bureau of Statistics collecting information on the socio-economic status of 53 ethnic minorities in 2015. Hanoi.

[7] Huynh, V. T. 1998. Culture and Ethnic Identity in Dong Nai. Biên Hòa: Dong Nai Publishing House.

[8] Huynh, V. T., Lam, N., \& Phan, D. D. 2013. The culture of the ethnic Cho-ro. Hanoi: Culture and Communication.

[9] Institute of Ethnology-Vietnam Social Science Committee. 1984. Ethnic Minorities in southern provinces of Vietnam. Hanoi: Social Sciences.

[10] Lam, N. 2010. The Marriage and Family of the ethnic Cho-ro of Dong Nai: Tradition and Change. Hanoi: National Culture.

[11] Ngo, V. L., \& Nguyen, V. D. 1992. Central Highlands Plateau: Potential and Prospects. Ho Chi Minh City Publishing House.

[12] Ngo, V. L, Nguyen, V. T., \& Nguyen, V. D. 1998. The cultures of ethnic minorities in Vietnam. Hanoi: Education.

[13] Nguyen, V. H. (ed.). 1997.Pictures of Vietnamese Ethnic Groups. Hanoi: Education.

[14] Nguyen, K. T. 1994. Vietnamese Traditional Houses. Hanoi: Vietnam Association for Historical Sciences.

[15] Schliesinger, Joachim. 1997. Hill Tribes of Vietnam 1: Introduction and Overview, Volume 1, Bangkok: White Lotus. 